Andrij Andrukhiv ${ }^{1}$, Bohdan Sokil ${ }^{2}$, Mariia Sokil ${ }^{3}$

1. Scientific Library, Lviv Polytechnic National University, Ukraine, Lviv, Profesorska Street, 1, E-mail: andriy.i.andrukhiv@1pnu.ua

2. Department of Engineering Mechanics, Hetman Petro Sahaidachnyi National Army Academy, Ukraine, Lviv, Heroes of Maidan Street, 32, E-mail: Bogdan.I.Sokil@lpnu.ua

3. Department of Transport Technologies, Lviv Polytechnic National University, Ukraine, Lviv, Stepan Bandera Street, 12, E-mail: Mariia.B.Sokil@lpnu.ua

\title{
ASYMPTOTIC METHOD IN INVESTIGATION OF COMPLEX NONLINEAR OSCILLATIONS OF ELASTIC BODIES
}

Received: October 11, 2018 / Revised: November 23, 2018 / Accepted: December 26, 2018

(C) Andrukhiv A., Sokil B., Sokil M., 2018

Abstract. The main provisions of the methodology of the study of complex oscillations of elastic bodies are outlined. Its main idea is as follows: a) on the basis of empirical studies, the change of the basic parameters of some forms of oscillation (usually smaller amplitude) is approximated by their analytical relations; b) these relationships are taken into account when constructing a mathematical model of the elastic body; c) for constructing and studying the solution of the obtained mathematical model of the process dynamics, the main ideas of the asymptotic integration of equations with partial derivatives are used.

Taken together, this allows us to obtain a two-parameter set of solutions that take into account the influence on the dynamics of the process of external and internal factors. The methodology is illustrated by the example of an elastic body, which simultaneously performs longitudinal and transverse vibrations. With the its aid it is established that resonant processes can exist in an elastic body not only by external actions, but also by the mutual influence of some forms of oscillation on others. The obtained results can serve as the basis for the choice of operating parameters of elastic elements of machines that carry out complex oscillations.

Keywords: nonlinear-elastic body, asymptotic methods, amplitude, resonance, complex oscillations.

\section{Statement of the problem}

The analysis of dynamic processes in mechanical systems, which include elements with distributed parameters, shows that in most cases, the latter carry out complex oscillations. They combine the longitudinal, bending, and in some cases torsional oscillations. The isolation of some of them, which have the largest amplitude (with the simultaneous neglect of the influence on them of others with small amplitude), can lead to significant inaccuracies in describing the dynamic process of the given element or all system. The magnitude of the error during such a simplified approach to the analytical description of the dynamic process of elastic bodies increases significantly in cases where the frequencies of the components of the oscillations are close to the values (bound by rational relations) and in cases where the elastic properties of the investigated element are described by nonlinear relations.

On the other hand, the analytical study of complex dynamic processes in elastic bodies based on mathematical models that take into account a wide range of external and internal factors is associated with significant difficulties. They include the integration of systems of partial differential equations with boundary conditions, which are determined by external interaction with others bodies at its ends. Therefore, there is a problem of developing such an analytical method, which, on the one hand, would take into account the wide range of factors influencing on it, and on the other hand, it would be available for engineering calculations. Partial solution of such problem is illustrated in this work by an example of an 


\section{Asymptotic Method in Investigation of Complex Nonlinear Oscillations of Elastic Bodies}

elastic body that simultaneously perform bending and longitudinal oscillations. An analytic-empirical method develops for this purpose. Its main idea is as follows: on the basis of empirical information on component oscillations (usually less amplitude), they are described by their approximate analytical relations; the obtained dependence is taken into account in the refined mathematical model of other oscillations; for the latter, which is relatively simple, one of the most convenient analytical methods is used.

\section{Materials and methods}

For the analytical study of simple nonlinear oscillation processes of systems with distributed parameters, the most effective methods are those, which based on the main idea of perturbation methods $[1,2]$. They are used effectively to study one [3-5] or multi-frequency oscillations $[2,6,7]$ of elastic bodies, as well as to systems with distributed parameters that are characterized by a longitudinal component of the velocity [7-10]. However, the operation of actually existing structures is accompanied, as a rule, by complex oscillations of their elements, for example, rotors of turbines simultaneously perform bending and twisting oscillations [11, 12], columns for drilling of oil and gas wells - longitudinal bending and twisting oscillations $[13,14]$ etc. Some experimental and theoretical studies show that the components of the oscillations of the elements of structures in individual cases, interacting with each other, can lead to significant dynamic loads in them. To prevent such phenomena, in advance, information about the reaction of the investigated element on one or another kind of perturbations, as well as the result of the interaction of certain types of oscillations, is necessary. Most accurately, it could be obtained based on adequate physical and, accordingly, mathematical models. However, to study the complex oscillations of even the simplest physical models of structural elements, there are mathematical difficulties. To overcome them in recent years, has gained a new impetus the development of the method, which is based on the use of partial information about the dynamics of the process $[15,16]$. Further use of it in a mathematical model makes it simpler, and on the other hand, it allows to trace such complex processes as resonant phenomena caused by external factors and the process of interaction of some oscillations with others (internal resonances [13, 17]).

As noted above, the purpose of the work is to develop a method for studying complex nonlinear oscillations of one-dimensional models of elastic bodies, more precisely elastic bodies that carry both bending and longitudinal oscillations. The main idea of the method is based on a priori information for the one of the oscillations. In the case under consideration, this is the amplitude-frequency characteristic of the longitudinal oscillations of the elastic body. Therefore, it is assumed that one of the parameters of this characteristic of the dynamic process of an elastic body (amplitude) assumes small values in comparison with the amplitude of bending oscillations. In spite of this, the effect of longitudinal oscillations on bending may increase over the time and at the expense of the latter in elastic bodies, even extremely dangerous resonance processes may occur. In order to predict and describe them first of all, it is necessary to construct the mathematical model of the investigated process. It is assumed in the work that bending oscillations occur in one plane XOY, and the axis OY coincides with the statically balanced position of the elastic body. In this case, the components of the displacement of the body section with coordinates are determined by two functions: $w(y, t)$ - transverse; $v(y, t)$ - longitudinal. The amplitude of longitudinal oscillation is much smaller than the bending amplitude, and on the basis of empirical studies with a sufficient degree of accuracy it can be described by the relationship $u(y, t)=b \sin \frac{\kappa}{l} y \cos (\Omega t+\phi)$, where $b$ is an amplitude of longitudinal oscillations, $\Omega$ is their frequency, $k, \phi$ are the constants and $l$ is the distance between points of fixation of an elastic body).

We note that:

a) in the work it is assumed that the ends of the body are hinged, and therefore their displacement is equal to zero. It allows the boundary conditions for the function $w(y, t)$ write in the form 


$$
w(y, t)_{\mid y=j}=0,{\frac{\partial^{2} w}{\partial y^{2}}}_{\mid y=j}=0, j=0, l,
$$

where $\kappa=k \pi, k=1,2, \ldots$

b) a more complex case of nonlinear longitudinal oscillations of the body may be the subject of separate studies.

\section{Solving procedure}

The basis for solving this problem is the differential equation for the transverse component of the displacement of the elastic body, which takes into account the known appearance of the longitudinal oscillation and the corresponding boundary conditions. To obtain it, it is necessary to consider the effect of given longitudinal oscillations on transverse, that is, "dynamic equilibrium" of the conditionally selected element of the body with the lengths $d y$ under the case that it is in a complex movement. Assuming that it moves in the direction perpendicular to the axis $\mathrm{OY}$ in the portable, then the relative component will be directed along the tangent to the curved axis of the elastic body. It means that a relative acceleration of the point that coincides with its middle can be represented in the form $\vec{a}_{r}=\vec{i} \frac{\partial^{2} u}{\partial t^{2}} \cos \alpha+\vec{j} \frac{\partial^{2} u}{\partial t^{2}} \sin \alpha$, where $\vec{i}, \vec{j}$ are the vectors which directed along the axes OX and OY, $\alpha$ is the angle of inclination to the vertical of the single vector of the tangent to the curved axis of the elastic body. Therefore for small oscillations $\sin \alpha=\alpha=\frac{\partial w}{\partial y}, \cos \alpha=1$. According to the definition of the Coriolis acceleration (taking into account the above), we have $\vec{a}_{c o r}=-2 \vec{i} \frac{\partial^{2} w}{\partial y \partial t} \frac{\partial u}{\partial t} \frac{\partial w}{\partial y}+2 \vec{j} \frac{\partial^{2} w}{\partial y \partial t} \frac{\partial u}{\partial t}$. These allows with a sufficient degree of accuracy the differential equation, which describes the flexural component of the oscillations of an elastic body, write in the form

$$
\rho \frac{\partial^{2} w}{\partial t^{2}}+E I \frac{\partial^{4} u}{\partial y^{4}}=\varepsilon f_{1}\left(w, \frac{\partial w}{\partial t}, \ldots, \frac{\partial^{3} w}{\partial y^{3}}, \gamma\right)+\rho b \Omega \sin \frac{\kappa}{l} y\left(\Omega \frac{\partial w}{\partial y} \cos (\Omega t+\phi)+2 \frac{\partial^{2} w}{\partial y \partial t} \sin (\Omega t+\phi)\right) .
$$

We denote by $\rho$ the mass of the unit of the length of the elastic body, by $E I$ its stiffness to the bend ( $E$ is the elastic modulus of the first kind, $I$ is the moment of inertia of the transverse section of the body), by $f\left(w, \frac{\partial w}{\partial t}, \ldots, \frac{\partial^{3} w}{\partial y^{3}}, \gamma\right)$ the function that describes resistance forces, the nonlinear component of the restoring force, the external $2 \pi$-periodic with respect to $\gamma$ perturbation with the frequency $\mu$ $(\gamma=\mu t)$ and other forces, the maximum value of which is significantly smaller than the maximum values of the terms of the left parts, on which indicate by the small parameter $\varepsilon$. At the same time, it follows that the vertical component of the Coriolis force of the inertia of the elastic body affects the dynamic component of the fixation reactions.

Thus, the problem was reduced to the construction and investigation of the solution of the differential equation (2) with boundary conditions (1). The restrictions on the right-hand side of the obtained equation allow for the construction of its one-frequency solution to use the general idea of the Van der Pol method adapted for systems with distributed parameters [4]. Consequently, one frequency solution of the boundary value problem (1), (2) we represent in the form

$$
w(t, y)=a_{s}(t)\left(\sin \left(\chi_{s} y+\omega_{s} t+\psi_{s}(t)\right)+\sin \left(\chi_{s} y-\omega_{s} t-\psi_{s}(t)\right)\right) .
$$

In formula (3), $a_{s}(t), \psi_{3}(t)$ are the unknown functions, which are defined in such a way that it, with the accuracy of quantities of the order $\varepsilon$, satisfies the original equation, with $\chi_{s} \omega_{S}$ such as 
Asymptotic Method in Investigation of Complex Nonlinear Oscillations of Elastic Bodies $\chi_{s}=\frac{s \pi}{l}, s=1,2, \ldots, \omega_{s}=\chi_{s}^{2} \sqrt{\frac{E I}{\rho}}$.

Differentiating (3) with respect to $t$ and $y$ we get

$$
\begin{gathered}
\frac{\partial w_{s}(t, y)}{\partial t}=a_{s} \frac{d \bar{\psi}_{s}}{d t}\left(\cos \left(\chi_{s} y+\bar{\psi}_{s}\right)-\cos \left(\kappa_{s} y-\bar{\psi}_{s}\right)\right)+\frac{d a_{s}}{d t}\left(\sin \left(\chi_{s} y+\bar{\psi}_{s}\right)+\sin \left(\chi_{s} y-\bar{\psi}_{s}\right),\right. \\
\frac{\partial^{2} w_{s}(t, z)}{\partial t^{2}}=-\frac{d a_{s}}{d t} \omega_{s}\left(\sin \left(\chi_{s} y+\bar{\psi}_{s}\right)+\sin \left(\chi_{s} y-\bar{\psi}_{s}\right)\right)+ \\
+a_{s} \omega_{s} \frac{d \bar{\psi}_{s}}{d t}\left(\cos \left(\chi_{s} y+\bar{\psi}_{s}\right)-\cos \left(\chi_{s} y-\bar{\psi}_{s}\right)\right) \\
\frac{\partial w}{\partial y}=a_{s}(t) \chi\left(\cos \left(\chi_{s} y+\bar{\psi}_{s}(t)\right)+\cos \left(\chi_{s} y-\bar{\psi}_{s}(t)\right)\right), \\
\frac{\partial^{4} w}{\partial y^{4}}=a_{s}(t) \chi^{4}\left(\sin \left(\chi_{s} y+\bar{\psi}_{s}(t)\right)+\sin \left(\chi_{s} y-\bar{\psi}_{s}(t)\right)\right), \bar{\psi}_{s}(t)=\omega_{s} t+\psi_{s}(t) .
\end{gathered}
$$

Denote that: a) representation in the form (3) holds for so-called "short" systems [5]. In a more complex case, the parameters $a_{s} \psi_{3}$ also depend on the linear variable. This case may be the subject of a separate study; b) in accordance with the Van -der-Poll method, it is accepted

$$
-a_{s} \frac{d \psi_{s}}{d t}\left(\cos \left(\kappa y+\bar{\psi}_{s}\right)-\cos \left(\kappa y-\bar{\psi}_{s}\right)\right)+\frac{d a_{S}}{d t}\left(\sin \left(\kappa_{s} y+\bar{\psi}_{s}\right)+\sin \left(\kappa_{S} y-\bar{\psi}_{S}\right)\right)=0 .
$$

Substituting dependences (3), (4), (5) into the original equation (2), we conclude

$$
\begin{gathered}
\frac{d a_{s}}{d t} \omega_{s} \sin \chi_{s} y \cos \bar{\psi}_{s}-a_{s} \omega_{s} \frac{d \psi_{s}}{d t} \sin \chi_{s} z \sin \bar{\psi}_{s}= \\
=\frac{\varepsilon}{2 \rho} \tilde{f}\left(a_{s}, y, \bar{\psi}_{s}, \gamma\right)+a_{s} \chi_{s} b \Omega \sin \frac{\kappa}{l} y \cos \chi_{s} y\left(\Omega \cos \bar{\psi}_{s} \cos (\Omega t+\phi)+\omega_{s} \sin \bar{\psi}_{s} \sin (\Omega t+\phi)\right),
\end{gathered}
$$

where $\frac{\varepsilon}{\rho} \tilde{f}\left(a_{s}, y, \bar{\psi}_{s}, \gamma\right)$ is a known function, which correspond to $\varepsilon f_{1}\left(w, \frac{\partial w}{\partial t}, \ldots, \frac{\partial^{3} w}{\partial y^{3}}, \gamma\right)$ under the condition that $w(t, y)$ and its derivatives are defined by (4), (5).

We will treat the relationship (6) with condition (5) as a system of differential equations that defines unknown functions $a_{S}(t), \psi_{3}(t)$. Solving it with respect to the derivatives of these functions (after the process of averaging over a linear variable), we obtain

$$
\begin{gathered}
\left.\frac{d a_{s}}{d t}=\frac{\varepsilon}{2 l \rho \omega_{s}} \int_{0}^{l}\left\{+\chi_{s} a_{s} b \frac{\Omega}{\omega_{s}} \sin \frac{\kappa}{l} y \sin 2 \chi_{s} y\left(\Omega \cos ^{2} \bar{\psi}_{s} \cos \theta+\omega_{s} \sin 2 \bar{\psi}_{s} \sin \theta\right)\right)\right\} d y, \theta=\Omega t+\phi, \\
\frac{d \psi_{s}}{d t}=\frac{\varepsilon}{2 l \rho a_{s} \omega_{s}} \int_{0}^{l}\left\{\begin{array}{c}
\left\{\bar{\psi}_{s}, \gamma\right) \sin \chi_{s} y \cos \bar{\psi}_{s}+ \\
\left.+\chi_{S} a_{s} b \frac{\Omega}{\omega_{s}} \sin \frac{\kappa}{l} y \sin 2 \chi_{s} y\left(\frac{1}{2} \Omega \sin 2 \bar{\psi}_{s} \cos \theta+2 \omega_{s} \sin ^{2} \bar{\psi}_{s} \sin \theta\right)\right\} d y .
\end{array}\right.
\end{gathered}
$$

The right-hand sides of non-autonomous differential equations (7) are periodic in phases $\bar{\psi}_{s}, \gamma, \theta$ with a period $2 \pi$, therefore, for the dynamic process, they describe the possible following cases: a) nonresonant; b) resonance caused by external periodic perturbation; c) resonance caused by longitudinal oscillations. We first consider the simplest, nonresonant case of complex oscillations of an elastic body. As shown in [2], for the first approximation of the asymptotic solution of non-autonomous systems with distributed parameters, small periodic perturbations do not affect the magnitude of the change in the 


\section{Andrij Andrukhiv, Bohdan Sokil, Mariia Sokil}

defining parameters of the oscillations, but only on their form. It means that for a nonresonance case, the system of differential equations (7) can be replaced on more simply, namely

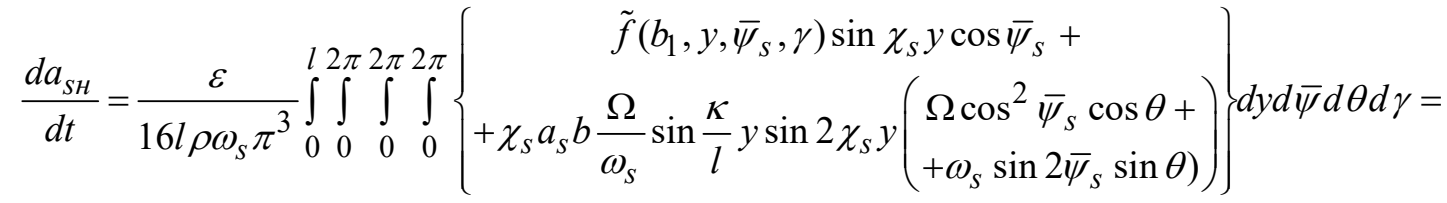

$$
\begin{aligned}
& =\frac{\varepsilon}{8 l \rho \omega_{s} \pi^{2}} \int_{0}^{l} \int_{0}^{2 \pi} \int_{0}^{2 \pi}\left\{\tilde{f}\left(b_{1}, y, \bar{\psi}_{s}, \gamma\right) \sin \chi_{s} y \cos \bar{\psi}_{s}\right\} d y d \bar{\psi}_{S} d \gamma \\
& \frac{d \psi_{s H}}{d t}=\frac{\varepsilon}{16 l \rho a_{s} \omega_{s} \pi^{3}} \int_{0}^{l} \int_{0}^{2 \pi} \int_{0}^{2 \pi} \int_{0}^{2 \pi}\left\{+\chi_{s} a_{s} b \frac{\Omega}{\omega_{S}} \sin \frac{\kappa}{l} y \sin 2 \chi_{s} y\left(\begin{array}{c}
\left.\frac{1}{2} \Omega \sin 2 \bar{\psi}_{s} \cos \theta+\right) \\
+2 \omega_{s} \sin ^{2} \bar{\psi}_{s} \sin \theta
\end{array}\right)\right\} d y d \bar{\psi} d \theta d \gamma= \\
& =\frac{\varepsilon}{8 l \rho a_{s} \omega_{s} \pi^{2}} \int_{0}^{l} \int_{0}^{2 \pi} \int_{0}^{2 \pi}\left\{\tilde{f}\left(b_{1}, y, \bar{\psi}_{s}, \gamma\right) \sin \chi_{s} y \sin \bar{\psi}_{s}\right\} d y d \bar{\psi} d \gamma .
\end{aligned}
$$

Thus, in the case where the frequency of bending and longitudinal oscillations of the elastic body is substantially different, small longitudinal oscillations do not affect the defining parameters of bending oscillations, but partly change their shape.

Resonant oscillations caused by external periodic perturbation. In the general case of the indicated resonant oscillations between the intrinsic frequency $\omega_{s}$ and the frequency of forced oscillations $\mu$, there is a connection that can be described by the dependence $\omega_{s}=\frac{p}{q} \mu$; where $p, q$ are mutually prime numbers. However, in nonlinear mechanical systems, as a rule, a dynamic process with a frequency close to the first fundamental frequency of oscillations is established, therefore, we will assume that, without further reducing the universality, we will assume $q \omega_{1}=p \mu$. In addition, the resonance of mechanical systems, more precisely, the amplitude of passage through the resonance is determined not only by physical and mechanical factors, but also by the difference in the phases of the own and forced oscillations. Formally entering the given parameter $\vartheta=\bar{\psi}_{1}-\frac{p}{q} \gamma \Rightarrow \bar{\psi}_{1}=\frac{p}{q} \gamma+\vartheta$ into the system of differential equations (7) after averaging over the phases of own and forced oscillations, we obtain

$$
\begin{gathered}
\frac{d a_{1 \text { рез }}}{d t}=\frac{\varepsilon}{4 l \rho \omega_{1} \pi} \int_{0}^{l} \int_{0}^{2 \pi}\left\{\tilde{f}\left(a_{1 \text { peз }}, y, \frac{p}{q} \gamma+\vartheta, \gamma\right) \sin \chi_{1} y \cos \left(\frac{p}{q} \gamma+\vartheta\right)\right\} d y d \gamma, \\
\frac{d \vartheta}{d t}=\omega_{1}-\frac{p}{q} \mu+\frac{\varepsilon}{4 l \rho a_{1 p e_{3}} \omega_{1} \pi} \int_{0}^{l} \int_{0}^{2 \pi}\left\{\tilde{f}\left(a_{1 p e_{3}}, y, \frac{p}{q} \gamma+\vartheta, \gamma\right) \sin \chi_{1} y \sin \left(\frac{p}{q} \gamma+\vartheta\right)\right\} d y d \gamma .
\end{gathered}
$$

For the case of the main resonance caused by the external periodic perturbation ( $p=q=1)$, they are transformed into the view

$$
\begin{gathered}
\frac{d a_{1 p e 3}}{d t}=\frac{\varepsilon}{4 l \rho \omega_{1} \pi} \int_{0}^{l} \int_{0}^{2 \pi}\left\{\tilde{f}\left(a_{1 p e_{3}}, y, \gamma+\vartheta, \gamma\right) \sin \chi_{1} y \cos (\gamma+\vartheta)\right\} d y d \gamma, \\
\frac{d \vartheta}{d t}=\omega_{1}-\mu+\frac{\varepsilon}{4 l \rho a_{1 p e_{3}} \omega_{1} \pi} \int_{0}^{l} \int_{0}^{2 \pi}\left\{\tilde{f}\left(a_{1 p e_{3}}, y, \gamma+\vartheta, \gamma\right) \sin \chi_{1} y \sin (\gamma+\vartheta)\right\} d y d \gamma .
\end{gathered}
$$

Thus, in the resonance case on the frequency of the external periodic perturbation, small longitudinal oscillations do not affect the amplitude of the resonance.

Resonance transverse oscillations caused by longitudinal oscillations. This case takes place, as 


\section{Asymptotic Method in Investigation of Complex Nonlinear Oscillations of Elastic Bodies}

follows from the relations (8), for the fulfillment of the condition $\omega_{S}=\frac{m}{n} \Omega ; m, n$ are mutually prime numbers. Proceeding in the same way as for the resonance at the frequency of the external periodic perturbation from the differential equations (7), we obtain

$$
\begin{aligned}
\frac{d a_{\text {spe } 3}}{d t}=\frac{\varepsilon}{8 l \rho \omega_{s} \pi^{2}} \int_{0}^{l} \int_{0}^{2 \pi} \int_{0}^{2 \pi}\left\{\begin{array}{c}
\tilde{f}\left(a_{\text {spes }}, y, \frac{m}{n} \theta+\bar{\vartheta}, \gamma\right) \sin \chi_{s} y \cos \left(\frac{m}{n} \theta+\bar{\vartheta}\right)+ \\
+\chi_{s} a_{\text {spes }} b \frac{\Omega}{\omega_{s}} \sin \frac{\kappa}{l} y \sin 2 \chi_{s} y \times \\
\left.\left.\times\left(\Omega \cos ^{2}\left(\frac{m}{n} \theta+\bar{\vartheta}\right) \cos \theta+\omega_{s} \sin 2\left(\frac{m}{n} \theta+\bar{\vartheta}\right) \sin \theta\right)\right)\right\} d y d \gamma d \theta
\end{array}\right\} \\
\frac{d \bar{\vartheta}}{d t}=\omega_{s}-\frac{m}{n} \Omega+\frac{\varepsilon}{8 l \rho \omega_{s} a_{\text {se3 }} \pi^{2}} \times \\
\quad \times \int_{0}^{l} \int_{0}^{2 \pi} \int_{0}^{2 \pi}\left\{\begin{array}{c}
\tilde{f}\left(a_{\text {spes }}, y, \frac{m}{n} \theta+\bar{\vartheta}, \gamma\right) \sin \chi_{s} y \sin \left(\frac{m}{n} \theta+\bar{\vartheta}\right)+ \\
+\chi_{s} a_{\text {spes }} b \frac{\Omega}{\omega_{s}} \sin \frac{\kappa}{l} y \sin 2 \chi_{s} y \times \\
\times\left(\frac{1}{2} \Omega \sin 2\left(\frac{m}{n} \theta+\bar{\vartheta}\right) \cos \theta+2 \omega_{s} \sin ^{2}\left(\frac{m}{n} \theta+\bar{\vartheta}\right) \sin \theta\right)
\end{array}\right\} d y d \gamma d \theta,
\end{aligned}
$$

where $\bar{\vartheta}$ is the phase difference between the self-bending and longitudinal oscillations, i.e. $\bar{\vartheta}=\bar{\psi}_{s}-\frac{m}{n} \theta \Rightarrow \bar{\psi}_{s}=\frac{m}{n} \theta+\bar{\vartheta}$. We simplify the obtained system of differential equations for determining the law of variation of the amplitude of internal resonance taking into account the following measures:

- for the first, the function $f\left(w, \frac{\partial w}{\partial t}, \ldots, \frac{\partial^{3} w}{\partial y^{3}}, \gamma\right)$ does not depend on the parameters that describe the longitudinal oscillations of the elastic body, therefore

$$
\begin{aligned}
\int_{0}^{l} \int_{0}^{2 \pi} \int_{0}^{2 \pi} \tilde{f}\left(a_{\text {spe }}, y, \frac{m}{n} \theta+\bar{\vartheta}, \gamma\right) \sin \chi_{s} y\left\{\begin{array}{l}
\cos \left(\frac{m}{n} \theta+\bar{\vartheta}\right) \\
\sin \left(\frac{m}{n} \theta+\bar{\vartheta}\right)
\end{array}\right\} d y d \gamma d \theta= \\
\quad=\int_{0}^{l} \int_{0}^{2 \pi} \int_{0}^{2 \pi} \tilde{f}\left(a_{\text {spes }}, y, \bar{\psi}, \gamma\right) \sin \chi_{s} y\left\{\begin{array}{l}
\cos \bar{\psi} \\
\sin \bar{\psi}
\end{array}\right\} d y d \gamma d \bar{\psi} ;
\end{aligned}
$$

- for the second,

$$
\int_{0}^{l} \sin \frac{\kappa}{l} y \sin 2 \chi_{s} y=\int_{0}^{l} \sin \frac{k \pi}{l} y \sin \frac{2 s \pi}{l} y=\left\{\begin{array}{l}
0 \text { npu } k \neq 2 s \\
\frac{l}{2} \text { npu } k=2 s
\end{array}\right\}
$$

therefore, internal resonances are possible on even forms of longitudinal oscillations;

- for the third,

$$
\int_{0}^{2 \pi} \sin 2\left(\frac{m}{n} \theta+\bar{\vartheta}\right) \sin \theta d \theta=
$$


Andrij Andrukhiv, Bohdan Sokil, Mariia Sokil

$$
\begin{aligned}
& =\frac{4 m n \cos \frac{m \pi}{n}}{4 m^{2}-n^{2}}\left\{\begin{array}{c}
\sin \frac{m \pi}{n}\left(1-2 \cos ^{2} \frac{m \pi}{n}\right)-2 \cos \frac{m \pi}{n} \sin ^{2} \frac{m \pi}{n} \sin 2 \bar{\vartheta}- \\
-2 \sin \frac{m \pi}{n}\left(1-2 \cos ^{2} \frac{m \pi}{n}\right) \cos ^{2} \bar{\vartheta}
\end{array}\right\}, \\
& \int_{0}^{2 \pi} \cos ^{2}\left(\frac{m}{n} \theta+\bar{\vartheta}\right) \cos \theta d \theta= \\
& =\frac{4 m n \cos \frac{m \pi}{n}}{4 m^{2}-n^{2}}\left\{\begin{array}{c}
\sin \frac{m \pi}{n}\left(1-2 \cos ^{2} \frac{m \pi}{n}\right)-2 \cos \frac{m \pi}{n} \sin ^{2} \frac{m \pi}{n} \sin 2 \bar{\vartheta}- \\
-2 \sin \frac{m \pi}{n}\left(1-2 \cos ^{2} \frac{m \pi}{n}\right) \cos ^{2} \bar{\vartheta}
\end{array}\right\}, \\
& \int_{0}^{2 \pi} \sin 2\left(\frac{m}{n} \theta+\bar{\vartheta}\right) \cos \theta d \theta=\frac{-16 m n \cos \frac{m \pi}{n}}{4 m^{2}-n^{2}}\left\{\begin{array}{c}
\cos \frac{m \pi}{n} \sin ^{2} \frac{m \pi}{n}-2 \cos \frac{m \pi}{n} \sin ^{2} \frac{m \pi}{n} \cos ^{2} \bar{\vartheta}+ \\
+\frac{1}{2} \sin \frac{m \pi}{n}\left(1-4 \cos ^{2} \frac{m \pi}{n}\right) \sin 2 \bar{\vartheta}
\end{array}\right\} \\
& \int_{0}^{2 \pi} \sin ^{2}\left(\frac{m}{n} \theta+\bar{\vartheta}\right) \sin \theta d \theta=\frac{-4 n^{2} \cos \frac{m \pi}{n}}{4 m^{2}-n^{2}}\left\{\begin{array}{c}
\cos \frac{m \pi}{n} \sin ^{2} \frac{m \pi}{n}-\frac{1}{2} \sin \frac{m \pi}{n}\left(2 \cos ^{2} \frac{m \pi}{n}-1\right) \sin 2 \bar{\vartheta}- \\
-2 \cos ^{2} \bar{\vartheta} \cos \frac{m \pi}{n} \sin ^{2} \frac{m \pi}{n}
\end{array}\right\} .
\end{aligned}
$$

It means that the combination resonances at the frequency of longitudinal oscillations take place under conditions $\frac{m}{n} \neq \frac{2 q+1}{2}, q=1,2, \ldots$

All these arguments allow state that the frequency of the lowest internal resonance corresponds to the second form of longitudinal oscillations ( $s=1, k=2$, at $m=1, n=2)$. Differential equations (13) in this case are transformed into a form

$$
\begin{gathered}
\frac{d a_{1 \text { рез }}}{d t}=\frac{\varepsilon}{8 l \rho \omega_{1} \pi^{2}} \int_{0}^{l} \int_{0}^{2 \pi} \int_{0}^{2 \pi} \tilde{f}\left(a_{\text {speз }}, y, \psi, \gamma\right) \sin \chi_{s} y \cos \psi d y d \psi d \gamma+ \\
+\chi_{1} a_{1 \text { pвз }} b \frac{\pi \Omega}{4 \rho \omega_{1}^{2}}\left(\Omega+2 \omega_{1}\right) \cos 2 \vartheta
\end{gathered}
$$

$\frac{d \bar{\vartheta}}{d t}=\omega_{1}-\frac{1}{2} \Omega+\frac{\varepsilon}{8 l \rho \omega_{1} a_{1 p 83} \pi^{2}} \int_{0}^{l} \int_{0}^{2 \pi} \int_{0}^{2 \pi} \tilde{f}\left(a_{p 83}, y, \psi, \gamma\right) \sin \chi_{s} y \sin \psi d y d \gamma d \theta+\chi_{1} b \frac{\pi \Omega}{4 \rho \omega_{1}^{2}}\left(\Omega+2 \omega_{1}\right) \sin 2 \vartheta$.

Assume that: a) the elastic properties of the investigated body satisfy the nonlinear technical law of elasticity [2]; b) the small resistance forces are proportional to the velocities in power S; c) the small external periodic perturbation varies according to the harmonic law, the function $\varepsilon f_{1}\left(w, \frac{\partial w}{\partial t}, \ldots, \frac{\partial^{3} w}{\partial y^{3}}, \gamma\right)$ takes the

form $\varepsilon f_{1}\left(w, \frac{\partial w}{\partial t}, \ldots, \frac{\partial^{3} w}{\partial y^{3}}, \gamma\right)=\varepsilon k_{1}\left(\frac{\partial w}{\partial t}\right)^{s}+\varepsilon k_{2} E I\left(3\left(\frac{\partial^{4} u}{\partial x^{4}}\left(\frac{\partial^{2} u}{\partial x^{2}}\right)^{2}+6\left(\frac{\partial^{3} u}{\partial x^{3}}\right)^{2} \frac{\partial^{2} u}{\partial x^{2}}\right)\right)+k_{3} \sin \mu t$, (coefficients $k_{1}, k_{2}$ and $k_{3}$ characterizes the magnitudes of the resistance force and periodic perturbation).

Then in the nonresonance case, as follows from the differential equations (8), the basic parameters of bending oscillations of an elastic body in the form close to the first form of "dynamic equilibrium" are 
described by the relations $\frac{d a_{1}}{d t}=\bar{k}_{1} a_{1}^{s}, \frac{d \psi}{d t}=\left(\frac{\pi}{l}\right)^{2} \sqrt{\frac{E I}{\rho}}-\frac{3 k_{2}}{128} a_{1}^{s}$. As for the main resonance at the frequency of the external periodic perturbation, then equations (11) are transformed in the indicated case to the view

$$
\begin{gathered}
\frac{d a_{1 \text { pез }}}{d t}=\overline{k_{1}} a_{1 \text { pes }}^{s},+\bar{k}_{2} \cos \vartheta \\
\frac{d \vartheta}{d t}=\left(\frac{\pi}{l}\right)^{2} \sqrt{\frac{E I}{\rho}}-\mu-\frac{3}{128} a_{1 \text { рез }}^{s}-\tilde{k}_{2} \sin \vartheta .
\end{gathered}
$$

For internal resonance in the case $m=1, n=2$ the equations which describe the change in the basic parameters of resonance bending oscillations take the form

$$
\begin{gathered}
\frac{d a_{1 p e 3}}{d t}=\bar{k}_{1} a_{1 p e 3}^{s},+\chi_{1} a_{1 p b} b \frac{\pi \Omega}{4 \rho \omega_{1}^{2}}\left(\Omega+2 \omega_{1}\right) \cos 2 \bar{\vartheta} \\
\frac{d \bar{\vartheta}}{d t}=\left(\frac{\pi}{l}\right)^{2} \sqrt{\frac{E I}{\rho}}-\frac{\pi}{l} \sqrt{\frac{E A}{\rho}}-\frac{3 k_{2}}{128} a_{1 p e 3}^{s}+\chi_{1} b \frac{\pi \Omega}{4 \rho \omega_{1}^{2}}\left(\Omega+2 \omega_{1}\right) \sin 2 \bar{\vartheta}
\end{gathered}
$$

\section{Results and Discussion}

Below, on the basis of equations (17), for different values of the parameters, the variation of the amplitude of transverse oscillations in the transition through the internal resonance for the following values of parameters is presented: $E=2,06 \times 10^{11} \mathrm{H} / \mathrm{m}^{2}, \rho=80.54 \mathrm{~kg} / \mathrm{m}$.

$a:\left\{\begin{array}{l}b=0.001 \text { м, brown } b=0.00125 \text { м, black, } \\ b=0.0015 \text { м , blue }, l=2 m, \omega_{1}=308 s^{-1} .\end{array} \quad b:\left\{\begin{array}{l}b=0.001 m, \text { black, } b=0.00125 m, \text { brown, } \\ b=0.0015 m, \text { blue }, l=3 m, \omega=136 \mathrm{~s}^{-1} .\end{array}\right.\right.$

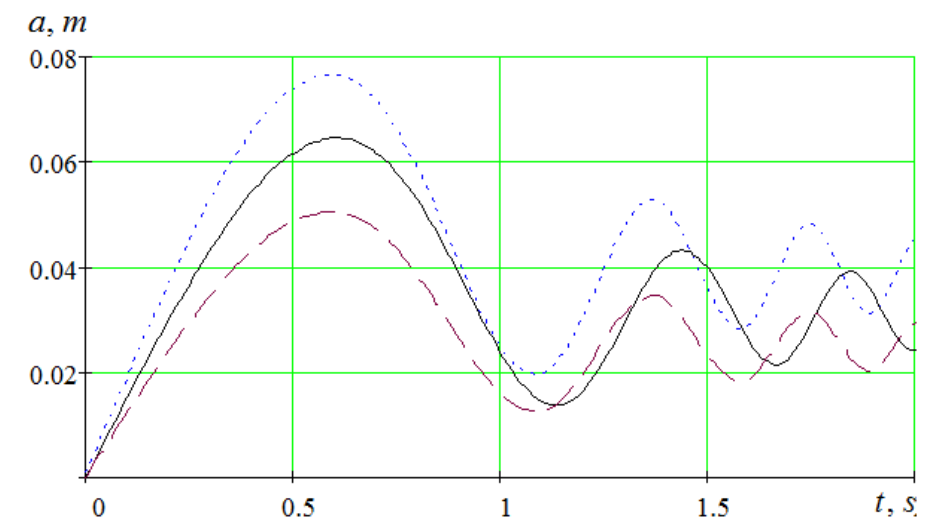

a

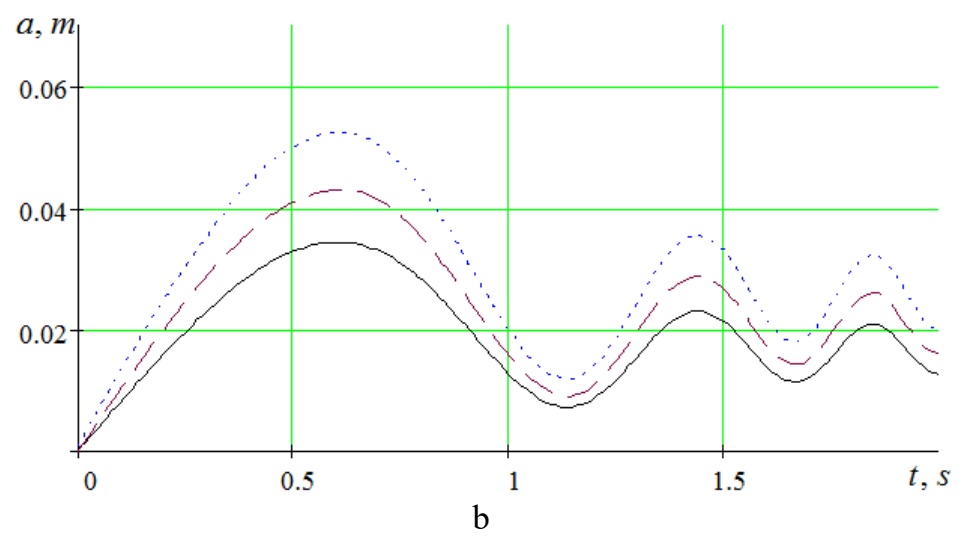

Fig. 1. Diagram of system function 


\section{Andrij Andrukhiv, Bohdan Sokil, Mariia Sokil}

\section{Conclusions}

For the elastic body, which performs bending and longitudinal oscillations, a method for identification the influence of the main external and internal factors on the determinant parameters of flexural variation is developed under the condition that the magnitude of the amplitude of the longitudinal oscillations is predetermined value which is significult less than the magnitude of the bending amplitudes. It is established on its base that:

- for the specified type of oscillation of the elastic body, possible bending resonance phenomena are caused by both external factors and longitudinal oscillations (internal resonances);

- internal resonances can exist only at frequencies that are proportional to the frequencies of pairwise modes of longitudinal oscillations;

- the amplitude of the transition through the resonance at the fundamental frequency of external perturbation takes less value for elastic bodies of greater flexural rigidity;

- the amplitude of bending oscillations in the "fast" transition through resonance at the frequency of external or internal perturbation is less than with "slow";

- the amplitude of the bending vibrations of the transition through the internal resonance at higher frequencies of longitudinal oscillations is less than at the second frequency of longitudinal oscillations.

The obtained results can serve as the basis for choosing the main technological and exploitation parameters of the elastic elements of mechanisms and machines that carry out complex oscillations.

\section{References}

[1] N. N. Bogoliubov, and Yu. A. Mitropolskii, Asimptoticheskie metody v teorii nelineinykh kolebanii [Asymptotic methods in the theory of nonlinear oscillations]. Moscow, Russia: Nauka Publ., 1974. [in Russian].

[2] Yu. A. Mitropolskii, and B. I. Moseenkov, Asimptoticheskie resheniia uravnenii v chastnykh proizvodnykh [Asymptotic solutions of partial differential equations]. Kyiv, Ukraine: Vyshcha shkola Publ., 1976. [in Russian].

[3] P. Ya Pukach, I. V. Kuzio, and M. B. Sokil, "Nelineinye izgibnye kolebaniia vrashchaiushchikhsia vokrug nepodvizhnoi osi tel i metodika ikh issledovaniia" ["Nonlinear bending vibrations of bodies rotating around a fixed axis and the method of their investigation"], Izvestiia vysshikh uchebnykh zavedenii. Gornyi zhurnal [Vibrations in technique and technologies], no. 7, pp. 141-149, 2013. [in Russian].

[4] B. I. Sokil, "Construction of asymptotic solutions of certain boundary-value problems for the nonautonomous wave equation”, Journal of Mathematical Sciences, no. 1 (96), pp. 2878-2882, 1999.

[5] Y. A. Mitropol'skii, and B. I. Sokil, "On the application of Ateb-functions to the construction of an asymptotic solution of the perturbed nonlinear Klein-Gordon equation", Ukrainian Mathematical Journal, no. 5 (50), pp. 754-760, 1998.

[6] S. N. Vladimirov, A. S. Maidanovskii, S. S. Novikov, Nelineinye kolebaniia mnogochastotnykh avtokolebatelnykh sistem [Nonlinear oscillations of multi-frequency self-oscillatory systems]. Tomsk, Russia: Izdatelstvo Tomskogo universiteta, 1993. [in Russian].

[7] Ye. Kharchenko, and M. Sokil, "Bahatochastotni kolyvannia odnovymirnykh neliniino pruzhnykh rukhomykh seredovyshch ta metodyka pobudovy asymptotychnykh nablyzhen kraiovykh zadach, shcho yikh opysuiut" ["Multifrequency oscillations of one-dimensional nonlinearly elastic moving media and a method for constructing asymptotic approximations of boundary value problems describing them"], Mashynoznavstvo [Mechanical Engineering], no. 1, pp. 19-25, 2007. [in Ukrainian].

[8] M. B. Sokil, A. I. Andrukhiv, O. I. Khytriak, "Zastosuvannia khvylovoi teorii rukhu ta asymptotychnoho metodu dlia doslidzhennia dynamiky deiakykh klasiv pozdovzhno-rukhomykh system" ["Application of the wave motion theory and the asymptotic method for studying the dynamics of some classes of longitudinal and moving systems"], Visnyk Natsionalnoho universytetu "Lvivska politekhnika" [Bulletin of Lviv Polytechnic National University], no. 730, pp. 114-118, 2012. [in Ukrainian].

[9] M. Sokil, "Neliniini kolyvannia hnuchkykh trubchastykh til, vzdovzh yakykh rukhaietsia sutsilnyi potik seredovyshcha" ["Nonlinear oscillations of flexible tubular bodies, along which a continuous flow of medium moves"], Naukovyi visnyk NLTU Ukrainy [Scientific Bulletin of UNFU], vol. 24.10, pp. 351-356, 2014. [in Ukrainian].

[10] B. I. Sokil, and M. B. Sokil, "Vymusheni kolyvannia hnuchkykh trubchastykh til, vzdovzh yakykh rukhaietsia sutsilnyi potik seredovyshcha" ["Forced oscillations of flexible tubular bodies, along which a continuous 


\section{Asymptotic Method in Investigation of Complex Nonlinear Oscillations of Elastic Bodies}

flow of medium moves"], Visnyk Natsionalnoho universytetu "Lvivska politekhnika" [Bulletin of Lviv Polytechnic National University], no. 866, pp. 60-65, 2017. [in Ukrainian].

[11] A. S. Goldin, Vibratciia rotornykh mashin [Vibration of rotary machines]. Moscow, Russia: Mashinostroenie Publ., 2000. [in Russian].

[12] A. V. Goroshko, and V. P. Roizman, "Issledovanie dinamiki i snizhenie vibroaktivnosti turbonasosnogo agregata putem resheniia obratnykh zadach" ["Study of the dynamics and reduction of vibroactivity of the turbopump assembly by solving inverse problems"], Mashinostroenie i inzhenernoe obrazovanie [Mechanical Engineering and Engineering Education], no. 1, pp. 29-35, 2014. [in Russian].

[13] P. I. Ohorodnikov, V. M. Svitlytskyi, and V. I. Hohol, "Doslidzhennia zv'iazku mizh pozdovzhnimy i krutylnymy kolyvanniamy burylnoi kolony" ["Investigation of the relationship between the longitudinal and torsional oscillations of the drill column"], Naftova haluz Ukrainy [Oil industry of Ukraine], no. 2, pp. 6-9, 2014. [in Ukrainian].

[14] V. I. Huliaiev, and O. I. Borshch, "Spiralni khvyli v zakruchenykh pruzhnykh trubchastykh sterzhniakh, shcho obertaiutsia z vnutrishnim potokom ridyny" ["Spiral waves in twisted elastic tubular rods, rotating with internal fluid flow"], Akustychnyi visnyk [Acoustic Bulletin], vol. 10, no. 3, pp. 12-18, 2007. [in Ukrainian].

[15] A. Andrukhiv, B. Sokil, and M. Sokil, "Resonant phenomena of elastic bodies that perform bending and torsion vibrations", Ukrainian Journal of Mechanical Engineering and Materials Science, vol. 4, no. 1, pp. 65-73, 2018 .

[16] A. V. Goroshko, V. P. Royzman, A. Bubulis, and K. Juzènas, "Methods for testing and optimizing composite ceramics-compound joints by solving inverse problems of mechanics", Journal of Vibroengineering, vol. 16, issue 5, pp. 2178-2187, 2014.

[17] I. U. Albert, V. A. Petrov, and A. E. Skvortsova, "Analiz dinamicheskoi reaktcii konstruktivnonelineinykh mekhanicheskikh sistem" ["Analysis of the Dynamic Response of Structural-Nonlinear Mechanical Systems"], Izvestiia VNIIG im. B. E. Vedeneeva [Proceeding of the VNIIG], vol. 241, pp. 38-59, 2002. [in Russian]. 